\title{
A multifactorial analysis of acceptance of evolution
}

\author{
Ryan D. P. Dunk ${ }^{1,2^{*}}$, Andrew J. Petto ${ }^{3}$, Jason R. Wiles ${ }^{1}$ and Benjamin C. Campbell ${ }^{2}$
}

\begin{abstract}
Background: Despite decades of education reform efforts, the percent of the general US population accepting biological evolution as the explanation for the diversity of life has remained relatively unchanged over the past 35 years. Previous work has shown the importance of both educational and non-educational (sociodemographic and psychological) factors on acceptance of evolution, but has often looked at such factors in isolation. Our study is among the first attempts to model quantitatively how the unique influences of evolutionary content knowledge, religiosity, epistemological sophistication, and an understanding of the nature of science collectively predict an individual's acceptance or rejection of evolution.

Results: Our study population had a high acceptance of evolution, with an average score of 77.17 (95\% C.I. \pm 1.483 ) on the Measure of Acceptance of the Theory of Evolution (MATE) instrument. Our combined general linear model showed that, of the variables in our model, an understanding of the nature of science explained the greatest amount of variation in acceptance of evolution. This was followed in amount of variance explained by a measure of religiosity, openness to experience, religious denomination, number of biology courses previously taken, and knowledge of evolutionary biology terms.

Conclusions: Understanding of the nature of science was the single most important factor associated with acceptance of evolution in our study and explained at least four times more variation than measures of evolutionary knowledge. This suggests that educational efforts to impact evolutionary acceptance should focus on increasing an understanding of the nature of science (which may be expected to have additional benefits towards generalized science denial). Additionally, our measure of epistemological sophistication had a unique, significant impact on acceptance of evolution. Both epistemological sophistication and an understanding of the nature of science are factors that might change throughout a liberal arts education, independent of the effect of direct evolutionary instruction.
\end{abstract}

Keywords: Acceptance of evolution, Nature of science, Epistemological sophistication, Religiosity, Knowledge of evolution, General linear model

\section{Background}

Evolution is the unifying theme of all biology. Living organisms and the interactions between them can be understood most clearly through the lens of evolution; this is reflected in the near-universal acceptance of evolution among biologists (Graffin 2003), who have studied the evidence supporting evolutionary theory and use it to guide their work. However, among the general public,

\footnotetext{
*Correspondence: rddunk@syr.edu

1 Department of Biology, Syracuse University, 110 Life Sciences Complex,

107 College Place, Syracuse, NY 13244, USA

Full list of author information is available at the end of the article
}

acceptance of evolution is much less prevalent. Despite decades of efforts toward science education reform that might be expected to improve evolutionary understanding and acceptance, little change has occurred in the number of people who accept evolutionary explanations of life's diversity (Gallup 2014). This rejection of biology's overarching theme leads to an inability to correctly understand and to reason appropriately regarding biological phenomena (Dobzhansky 1973). In addition, science denial by those responsible for setting policy leads to difficulties in implementation of sound science curricula in schools as well as poor potential outcomes regarding future funding for biological sciences. It is for these 
reasons and more that a public accepting of evolutionary biology is not only desirable, but necessary. In this study, we attempt to explore how different educational and sociodemographic factors interact with acceptance of evolution in college students.

Knowledge of evolution is perhaps the most intuitive factor related to evolution acceptance. Rutledge and Warden (2000) found that among high school teachers, knowledge of evolution was significantly correlated with acceptance of evolution (see also Deniz et al. 2008; Glaze et al. 2015). This link was also found in an undergraduate sample (Carter and Wiles 2014). Other studies (Heddy and Nadelson 2013; Mazur 2004; Wiles 2014) have found more generally that higher education levels lead to greater acceptance of evolution. Barone et al. (2014) found a significant correlation between knowledge of evolutionary terms and acceptance of evolution among visitors to a natural history museum. However, other researchers have found no significant link between knowledge and acceptance of evolution, especially when other variables are considered in the same model (Cavallo and McCall 2008; Sinatra et al. 2003).

Multiple studies have found an understanding of the nature of science to be significantly related to acceptance of evolution (Carter and Wiles 2014; Cavallo and McCall 2008; Glaze et al. 2015; Johnson and Peeples 1987; Rutledge and Mitchell 2002; Trani 2004). Compared to the more equivocal support of the role of evolutionary content knowledge in evolution acceptance described above, this consistent trend seems to indicate acceptance of evolution might be more strongly influenced by a general understanding of the aims and process of science. Indeed, many of the major creationist criticisms of evolutionary biology stem from a misunderstanding of the nature of science (Matthews 1997; Pigliucci 2008).

Cognitive factors have also been found to have a strong effect on acceptance of evolution. Deniz et al. (2008) found thinking dispositions to be the most significant predictor of evolution acceptance in preservice biology teachers in Turkey. Sinatra et al. (2003) found a measure of epistemological sophistication and a disposition towards actively open-minded thinking to be significantly correlated with acceptance of human evolution (but no relation was found for acceptance of animal evolution). Hawley et al. (2011) found that openness to experience, a psychological metric measuring intellectualism and creativity (John et al. 2008), to be significantly negatively related to acceptance of creationist reasoning. In this study, we consider epistemological sophistication to be a general term referring to a mature manner of understanding the nature of knowledge. Openness to experience is used here as a proxy for epistemological sophistication.
It is generally known that, at least among many Christian denominations in the United States, people who are more strongly religious tend to have greater concern over evolution, especially as it applies to humans. Many authors have found a link between strength of religious convictions and lack of acceptance of evolution (Barone et al. 2014; Carter and Wiles 2014; Glaze et al. 2015; Heddy and Nadelson 2013; Mazur 2004; Moore et al. 2011; Nehm and Schonfeld 2007; Trani 2004), although Hawley et al. (2011) found contradictory results. Religiosity, loosely defined as the degree to which religious faith and conviction have an impact on daily life, is a preferred measure over religious denomination because it indicates a level of religious activity and how strongly religion may influence understandings and decision making.

Combining the factors described above, we present a working model of evolutionary acceptance whereby acceptance of evolution is impacted separately by knowledge of evolution, religiosity, epistemological sophistication, and an understanding of the nature of science. As described previously, all of these factors have been shown to be related to acceptance of evolution. However, very few studies include multiple factors, and to our knowledge, none has quantitatively evaluated their comparative effects simultaneously. To correctly understand the relative impact each factor has, they must be analyzed in a model together, along with demographic variables. This is the aim of our study.

Specifically, we predicted that, when analyzed together in a general linear model, greater epistemological sophistication, evolutionary content knowledge, and understanding of the nature of science will each be associated with higher levels of acceptance of evolution, while higher levels of religiosity will be associated with lower levels of acceptance of evolution.

\section{Methods \\ Survey methodology}

To assess the relative importance of different variables on the acceptance of evolution in college students, we conducted a survey of 284 undergraduates in an introductory anatomy and physiology course at the University of Wisconsin-Milwaukee. This sample population is unlikely to be representative of the general population, but is likely comparable in most respects to students with similar experience at other institutions with regard to the variables being examined. The survey consisted of six sections, 1-2 pages each, for a total length of 188 items on 7 pages, exclusive of the consent form which served as a removable cover page. The sections were ordered to attempt to eliminate potential biases in response from subconscious priming (Strack 1992). All of the sections except the final one consisted of instruments developed and used in other studies (Table 1; 
see Additional file 1: Methods for a more detailed description of the survey instruments). These were included intact to allow for maximal comparison between the present study and others employing the same instruments.

The final portion of the survey consisted of demographic questions and other variables we thought might be related to acceptance of evolution. Participants were asked to provide via free response personal information about age, sex, ethnicity, religious denomination, perceived importance of church, frequency of church attendance, college major or concentration, number of college science classes taken, number of college biology classes taken, and rurality of childhood home. Participants were also asked to provide their net college grade point average [GPA; choices provided both numerical and descriptive approximation, e.g., "2.5-2.9 (Mix of Cs and Bs)"], general interest in science (on a 5-point Likert scale), and highest level of schooling completed by mother and father (asked separately: choices were less than high school, high school diploma or GED, some college, 2-year degree, 4-year degree, graduate education). All data collection, coding, and analyses were performed according to an ethics review board approved protocol.

\section{Data entry and coding}

All survey responses were electronically transcribed by one of three individuals, either one of the authors (RDPD), a graduate student assistant, or an undergraduate assistant. Terms from the terms index were marked as present or absent and all Likert questions were entered as answered. For the demographic questions, answers were entered verbatim except for small edits for clarity or brevity. Each survey was transcribed in duplicate by at least two individuals and checked for consistency by the first author. Free-response variables were coded separately by the first and last authors using the guide given in Additional file 1: Table S1 and compared for consistency. Where inconsistencies were found, both coders reached agreement via conference. The full dataset used to generate our results has been publicly archived along with supplemental materials on the figshare repository (doi: 10.6084/m9.figshare.5072137).

\section{Statistical methodology}

Summary statistics were calculated for all linear variables, and frequency tables were produced for all categorical and ordinal variables. For a few of our variables, the initial coding created inadequate sample sizes for some groups; we revised this by combining codes, and the final coding is reflected in Additional file 1: Table S1. A wide range of religious denominations with seven or fewer representatives were grouped under "other". This highly variable group was dropped from all subsequent analyses.

We selected the Measure of Acceptance of the Theory of Evolution (MATE; Rutledge and Warden 1999) as our dependent variable as it is a widely-used measure of acceptance of evolution that has been validated among university undergraduate students (Rutledge and Sadler 2007). The individual influence of each independent variable on students' MATE scores was tested using ordinary least-squares regression analyses for continuous variables, and for each categorical variable a one-way ANOVA was completed. Ordinal variables present in the dataset were treated as categorical variables; this was done for statistical simplicity, but it gives a conservative estimate of relative importance (Agresti 2010).

Variables that were found to have a significant effect on MATE score were included in a large, exploratory General Linear Model (specifically, a multifactorial ANCOVA without interaction) to explore their independent effects on MATE score. Variables that were found to affect MATE score in a significant or nearly significant way (using an $\alpha$ of 0.10) were chosen for inclusion in the final model.

Five variables were presumed to be measurements of religiosity. These included the Likert scale items "My religion impacts my daily life", "My religion influences my decisions", "I am a religious person", as well as frequency of church attendance and importance of church. These five variables were subjected to a principle components analysis with varimax rotation and were found to all form one highly consistent factor. However, the factor scores were not as robust in explaining variation in MATE scores as some of the individual components, so the factor was not used in our models.

Table 1 Survey instruments used in the present study and their original sources

\begin{tabular}{llll}
\hline Name of survey instrument & Citation & Portions used in present study & Variables measured \\
\hline $\begin{array}{l}\text { Familiarity with Evolutionary Terms } \\
\begin{array}{l}\text { Measure of the Acceptance of the Theory of } \\
\text { Evolution (MATE) }\end{array}\end{array}$ & $\begin{array}{l}\text { Barone et al. (2014) } \\
\text { Rutledge and Warden (1999) }\end{array}$ & Full & Knowledge of evolution \\
$\begin{array}{l}\text { Evolutionary Attitudes and Literacy Survey- } \\
\quad \text { Short Form (EALS-SF) }\end{array}$ & Short and Hawley (2012) & Three "religious activity" questions & Religiosity \\
$\begin{array}{l}\text { Big five inventory } \\
\text { Understanding of science }\end{array}$ & John et al. (2008) & Full & Openness to experience \\
\hline
\end{tabular}


The final model was again run as a multifactorial ANCOVA. Interaction terms between variables were not included as they could not be reliably estimated in the full model. To the limited extent interactions were able to be estimated, their relative contribution to the model was small. The final eight factors were assessed for adherence to the ANCOVA model. Specifically, the homogeneity of regression slopes was tested for and found to be upheld. Effect sizes were calculated as $\eta^{2}$ (Kline 2004). Analyses were conducted using SYSTAT or SPSS, except effect sizes which were calculated manually.

\section{Results}

The average MATE score was 77.17 (95\% C.I. \pm 1.483), right at the lower threshold of what is considered high acceptance (Rutledge and Sadler 2007). Scores ranged from 28 to 100 and thus all levels of acceptance had a sample of students (Table 2). On average, respondents tended to have a moderate level of familiarity with evolutionary terms, and were not particularly knowledgeable about the nature of science (Table 3). Demographically, our study was skewed young (mean age $=21.7$ ), white $(66.9 \%)$, and female $(69.7 \%)$, with a high proportion of health majors $(80.8 \%)$, who were not well experienced in biology (average number of college biology classes taken $=1.82$ ). In

Table 2 Number of respondents scoring within each level of evolution acceptance on the MATE

\begin{tabular}{llc}
\hline Acceptance level $^{\text {a }}$ & Score range & Number of respondents \\
\hline Very low & $20-52$ & 10 \\
Low & $53-64$ & 30 \\
Moderate & $65-76$ & 90 \\
High & $77-88$ & 101 \\
Very high & $89-100$ & 53
\end{tabular}

${ }^{a}$ Acceptance level and score range defined by Rutledge and Sadler (2007) most other measures, such as rurality of childhood home, GPA, and parents' levels of educational achievement, our population was more diverse (Tables 3, 4).

With regard to religion, our sample was heavily represented by Christian (57\%; including 3 orthodox Christians coded as "Other") and areligious (37\%) individuals. The remainder included a variety of other faiths. Among Christians, Catholics were the denomination group most strongly represented ( $26 \%$ of full sample), followed by Protestants and Non-Denominational Christians (a group which often is heavily composed of fundamentalist evangelicals and members of stand-alone "megachurches"; Table 4).

Looking across religious identities, those who claimed no religious affiliations scored highest on the MATE (mean: 83.14, 95\% C.I. \pm 2.124 ), followed by Catholics (mean: 76.76, 95\% C.I. \pm 2.433 ) and Protestants (mean: 72.68, 95\% C.I. \pm 4.826 ). Non-Denominational Christians had the lowest MATE score amongst denominational identities (mean: 67.31, 95\% C.I. \pm 3.615). However, while these results are in line with expected trends, we caution against generalizing our sample of college undergraduates to religious affiliations as a whole, especially regarding the high proportion of areligious individuals.

Table 5 shows the results for each variable's individual relation to the MATE. Regarding the linear variables, scores on both the understanding of science and Familiarity With Evolutionary Terms are significantly correlated with MATE score, as are number of both science and biology courses taken, age, and two of the factors from the Big Five Inventory, openness to experience and extraversion. All of these are positively correlated with the MATE except for extraversion (viz., increased extraversion leads to decreased score on the MATE). The other three factors from the big five inventory (neuroticism, conscientiousness, and agreeableness) did not have a statistically significant impact on MATE score.

Table 3 Summary statistics for linear variables

\begin{tabular}{lllll}
\hline Variable & Mean & Standard deviation & Minimum (min. possible) & Maximum (max. possible) \\
\hline MATE & 77.165 & 12.696 & $28(20)$ & $100(100)$ \\
Evolutionary Terms & 15.947 & 4.167 & $4(0)$ & $28(28)$ \\
Knowledge of the nature of science & 67.75 & 6.920 & $51(20)$ & $100(100)$ \\
Openness to experience & 34.643 & 5.578 & $18(10)$ & $48(50)$ \\
Conscientiousness & 32.179 & 4.826 & $15(9)$ & $45(45)$ \\
Extraversion & 27.046 & 5.665 & $14(8)$ & $40(40)$ \\
Agreeableness & 34.832 & 4.566 & $17(9)$ & $45(45)$ \\
Neuroticism & 23.611 & 5.385 & $10(8)$ & $39(40)$ \\
Age & 21.665 & 5.106 & 18 & 51 \\
Number of college science courses & 3.979 & 3.993 & 0 & 30 \\
Number of college biology courses & 1.813 & 2.573 & 0 & 22 \\
\hline
\end{tabular}


Table 4 Frequency tables for select categorical variables

\begin{tabular}{|c|c|c|}
\hline Variable & Category & Number \\
\hline \multicolumn{3}{|c|}{ Denomination } \\
\hline & Catholic & 72 \\
\hline & Protestant & 41 \\
\hline & Non-denominational Christian & 39 \\
\hline & None & 100 \\
\hline & Other & 21 \\
\hline & Total & 273 \\
\hline \multicolumn{3}{|c|}{ Religion influences decisions } \\
\hline & Disagree strongly & 94 \\
\hline & Disagree & 45 \\
\hline & Neither agree nor disagree & 52 \\
\hline & Agree & 60 \\
\hline & Agree strongly & 33 \\
\hline & Total & 284 \\
\hline \multicolumn{3}{|c|}{ Importance of Church } \\
\hline & 1 (low) & 92 \\
\hline & 2 & 73 \\
\hline & 3 & 36 \\
\hline & 4 & 20 \\
\hline & 5 (high) & 55 \\
\hline & Total & 276 \\
\hline \multicolumn{3}{|l|}{ Major } \\
\hline & Nursing & 63 \\
\hline & Other health majors & 118 \\
\hline & Biology & 16 \\
\hline & All others & 27 \\
\hline & Total & 224 \\
\hline \multicolumn{3}{|l|}{ Ethnicity } \\
\hline & White & 180 \\
\hline & Asian/Pacific Islander & 31 \\
\hline & Hispanic & 20 \\
\hline & Black & 19 \\
\hline & Other & 19 \\
\hline & Total & 269 \\
\hline \multicolumn{3}{|l|}{ Sex } \\
\hline & Female & 198 \\
\hline & Male & 86 \\
\hline & Total & 284 \\
\hline
\end{tabular}

Additional categorical variables are in Additional file 1: Table S2

Regarding the categorical variables, all five measures of religiosity showed significant association with the MATE, with denomination, interest in science, ethnicity, and sex showing significant relations as well. GPA, rurality of childhood home, major, mother's education level, and father's education level were not significant.

All of the variables with a significant solo association with MATE score were combined into an exploratory full ANCOVA (Additional file 1: Table S3). As previously noted, those variables with a significance at or below $\mathrm{p}=0.10$ in this exploratory model were included in a final ANCOVA model. The final analysis (given in Table 6) included five linear variables (understanding of science score, openness to experience, Familiarity With Evolutionary Terms score, extraversion, and number of college biology courses taken) and three categorical variables ("My religion influences my decisions", denomination, and importance of church in life). The significant terms in this final model explain $32.6 \%$ of the variation in MATE score in our study. Knowledge of the nature of science had the greatest association with MATE score, with over $13 \%$ variance uniquely explained. This was followed by the religiosity measure "My religion influences my decisions" (10.1\% variance explained), openness to experience $(5.1 \%)$, denomination (2.5\%), number of college biology courses taken (1.6\%), and Familiarity with Evolutionary Terms (1.2\%). Another religiosity measure (self-described importance of church) and extraversion were no longer significant in the final model.

One of the most important assumptions to be met in the ANCOVA model is homogeneity of regression slopes (Huitema 2011; Rutherford 2001): that is, for each level of a categorical variable, the regression lines of the dependent variable and a covariate must be parallel. This is borne out in our data. Significantly heterogeneous regression slopes were tested for by running single ANCOVAs (Myers and Well 2003). MATE score was the dependent variable and each covariate and categorical variable were paired in a two-way ANCOVA with an interaction term included. Significant interaction terms would signify significant heterogeneity; none were found to be significant, even without correction for multiple tests.

\section{Discussion}

Our survey showed an overall average score on the MATE of 77.17 (95\% C.I. \pm 1.483 ), which is at the lower cutoff for "high acceptance" as defined by Rutledge and Sadler (2007). Although high in comparison to other studies of college students (Deniz et al. 2008; Rutledge and Sadler 2007), gifted high school students (Wiles and Alters 2011), and biology teachers (Rutledge and Warden 1999), this average MATE score is nearly identical to that found in a sample of patrons of a natural history museum in the same region (Barone et al. 2014).

Our initial associations with MATE score showed a high impact of the knowledge of the nature of science, Familiarity with Evolutionary Terms, number of college biology and science courses taken, openness to experience, all religiosity measures, denomination, and interest in science, with a smaller but still significant relationship between MATE and ethnicity, sex, age, and extraversion (Table 5). However, once the variables were combined, many of them no longer retained significance. Ethnicity, 
Table 5 Raw (uncorrected) p-values of association with score on the Measure of Acceptance of the Theory of Evolution (MATE)

\begin{tabular}{|c|c|c|c|}
\hline A. Linear effects & Significance of effect on MATE ( $p$ value) & Adjusted $\mathrm{R}^{2}$ & Standard coefficient \\
\hline Knowledge of the nature of science & $9.992 \times 10^{-16}$ & 0.285 & 0.537 \\
\hline Evolutionary Terms & $6.907 \times 10^{-9}$ & 0.109 & 0.335 \\
\hline Number of college biology courses taken & $1.249 \times 10^{-5}$ & 0.062 & 0.256 \\
\hline Number of college science courses taken & $1.384 \times 10^{-5}$ & 0.062 & 0.255 \\
\hline Openness to experience & $1.000 \times 10^{-4}$ & 0.050 & 0.230 \\
\hline Age & 0.006 & 0.023 & 0.162 \\
\hline Extraversion & 0.037 & 0.012 & -0.124 \\
\hline Neuroticism & 0.398 (NS) & 0.000 & -0.051 \\
\hline Conscientiousness & 0.516 (NS) & 0.000 & -0.039 \\
\hline Agreeableness & 0.558 (NS) & 0.000 & -0.035 \\
\hline B. Categorical effects & Significance of effect on MATE (p-value) & F-ratio & Degrees of freedom (Num., Den.) \\
\hline "My religion influences my decisions" & $1.074 \times 10^{-21}$ & 31.565 & 4,279 \\
\hline Importance of Church & $9.556 \times 10^{-17}$ & 23.581 & 4,271 \\
\hline "My religion impacts my daily life" & $8.484 \times 10^{-14}$ & 18.949 & 4,279 \\
\hline Frequency of Church Attendance & $1.273 \times 10^{-12}$ & 17.260 & 4,270 \\
\hline "I am a religious person" & $5.024 \times 10^{-12}$ & 16.320 & 4,279 \\
\hline Denomination & $6.641 \times 10^{-12}$ & 20.508 & 3,248 \\
\hline Interest in science & $6.318 \times 10^{-5}$ & 7.639 & 3,280 \\
\hline Ethnicity & 0.021 & 2.944 & 4,264 \\
\hline Sex & 0.019 & 5.599 & 1,282 \\
\hline GPA & 0.196 (NS) & 1.574 & 3,280 \\
\hline Rurality of childhood home & 0.197 (NS) & 1.517 & 4,279 \\
\hline Major & 0.363 (NS) & 1.069 & 3,220 \\
\hline Mother's education level & 0.399 (NS) & 1.032 & 5,254 \\
\hline Father's education level & 0.818 (NS) & 0.443 & 5.250 \\
\hline
\end{tabular}

Table 6 Final ANCOVA model of the Measure of the Acceptance of the Theory of Evolution

\begin{tabular}{|c|c|c|c|c|c|c|}
\hline Source & Type III sums of squares & Degrees of freedom & Mean squares & F-ratio & p-value & $\eta^{2}$ \\
\hline Knowledge of the nature of science & 3249.268 & 1 & 3249.268 & 46.743 & $7.659 \times 10^{-11}$ & 0.1324 \\
\hline "My religion influences my decisions"R & 2483.838 & 4 & 620.959 & 8.933 & $1.042 \times 10^{-6}$ & 0.1012 \\
\hline Openness to Experience & 1246.317 & 1 & 1246.317 & 17.929 & $3.353 \times 10^{-5}$ & 0.0508 \\
\hline Number of college biology courses taken & 393.690 & 1 & 393.690 & 5.664 & 0.018 & 0.0160 \\
\hline Denomination & 621.326 & 3 & 207.109 & 2.979 & 0.032 & 0.0253 \\
\hline Evolutionary Terms & 302.351 & 1 & 302.351 & 4.360 & 0.038 & 0.0123 \\
\hline Importance of Church ${ }^{R}$ & 554.428 & 4 & 138.607 & 1.994 & 0.096 & \\
\hline Extraversion & 188.660 & 1 & 188.660 & 2.714 & 0.101 & \\
\hline Error & $15,501.361$ & 223 & 69.513 & & & \\
\hline
\end{tabular}

${ }_{\mathrm{R}}$ Denotes item that measures religiosity

age, number of college science courses taken, interest in science, sex, and three of the religiosity measures ("My religion impacts my daily life", "I am a religious person", and frequency of church attendance) all have p-values in the full ANCOVA much higher than 0.10 (Additional file 1: Table S3). This underscores the importance of our approach; the methods used in most previous studies would find and report significance for parents' education levels (Deniz et al. 2008), or sex (Grose and Simpson 1982) (or age or ethnicity) in acceptance of evolution; 
in our study, however, these relationships appear to be driven by underlying variation in other variables.

In the final ANCOVA model we found all variables that were significant in the "Full" exploratory model remained so. In addition, number of college biology courses becomes a significant predictor of score on the MATE due to the increased power of the test. Our final model provides support for all of the factors described earlier. All together, the significant terms in the final model explain nearly a third of the variance in MATE score; this is a satisfactory amount, especially for a model of human cognition, but it bears note that much of the variation in MATE score was left unexplained by the significant terms in our model.

The final model is striking in the order of the importance of its terms as well; nature of science knowledge explained over $13 \%$ of the variation in MATE score, and religiosity an additional $10 \%$. Evolutionary knowledge (measured in terms and number of courses combined) only accounts for about $2.8 \%$ of the variation, while openness to experience (our proxy for epistemological sophistication) explained nearly twice that amount (5.1\%). Finally, our study agrees with that of Barone et al. (2014) in finding a significant impact of religious denomination on MATE score, although we found that once religiosity and other measures were accounted for, the impact was greatly reduced (with $2.5 \%$ of variance explained).

\section{Conclusions}

These findings have direct implications for our understanding of evolution acceptance. We found that, in our sample, evolutionary content knowledge has a statistically significant but relatively small impact. This may account for the general long-term failure of pedagogical changes alone to effect changes in evolution acceptance. In order for future efforts to be more successful, they should include increased instruction on the nature of science. As students develop better understandings of the nature of science, this should have a direct, measurable impact on acceptance of evolution, at least in post-secondary settings. Furthermore, we take heart in the finding of the importance of openness to experience. While this psychological trait may not be simple to teach directly, we should hope that a liberal arts education would effect a change in related epistemological sophistication and hence increase evolution acceptance [which could account for the significant impact of educational attainment on evolution acceptance as seen in Barone et al. (2014)]. In regards to the importance of religiosity, rather than expecting or effecting change in levels of religiosity, which is neither the province nor the goal of science educators, an effective strategy may be to help reduce students' perceived conflicts between their religious identities and acceptance of evolution by discussing the matter frankly (Barnes and Brownell 2016; Barnes et al. 2017).

In conclusion, we found that acceptance of evolution is related to a variety of factors, some which are influenced by formal science education, and some that are not. Among education-related factors, the majority of the impact came from an understanding of the nature of science, which may be underemphasized in many levels of science education. For factors not related to formal science education we found that while religiosity explained the largest amount of variation, epistemological sophistication, which should be expected to change with increased educational exposure, was also important. Thus, both sets of factors can have an important contribution in changing evolutionary acceptance.

\section{Additional file}

Additional file 1. Supplemental methods and results.

\begin{abstract}
Abbreviations
GPA: grade point average; MATE: Measure of Acceptance of the Theory of Evolution.
\end{abstract}

\section{Authors' contributions}

RDPD and BCC conceived of the main portion of the study. AJP, RDPD, and $B C C$ were responsible for the administration of the survey. Data entry and coding was completed by BCC and RDPD. BCC, JRW, and AJP provided statistical guidance. RDPD conducted the statistics and created all tables. RDPD wrote the first draft of the manuscript. BCC, JRW, and AJP revised and rewrote the manuscript in collaboration with RDPD. All authors read and approved the final manuscript.

\section{Author details}

${ }^{1}$ Department of Biology, Syracuse University, 110 Life Sciences Complex, 107 College Place, Syracuse, NY 13244, USA. ${ }^{2}$ Department of Anthropology, University of Wisconsin-Milwaukee, PO Box 413, Milwaukee, WI 53201, USA. ${ }^{3}$ Department of Biological Sciences, University of Wisconsin-Milwaukee, PO Box 413, Milwaukee, WI 53201, USA.

\section{Acknowledgements}

Tara Gallagher and Kyia Hernandez assisted in administering and coding the surveys. Charles Zaiontz and Michael Clark provided useful information on effect size calculations in ANCOVA modeling. The Syracuse University Biology Education Research Group and Caitlin McDonough provided useful comments on this manuscript. The authors would like to thank them all for their assistance. The authors alone are responsible for the final manuscript.

\section{Competing interests}

The authors declare no competing interests, financial or otherwise.

\section{Availability of data and materials}

The dataset supporting the conclusions of this article will be made available in the figshare repository at https://figshare.com/s/fe4abb37e18df4a1289d (doi:10.6084/m9.figshare.5072137).

\section{Ethics approval and consent to participate}

All participants were provided with a removable consent form. Removal of the form upon submission was taken as consent. All participants were provided with an identifier upon submission and thus data was de-identified immediately upon collection. All procedures were reviewed and approved by 
the University of Wisconsin Milwaukee Institutional Review Board (Approval number 14.244, approved March 7, 2014).

\section{Funding}

RDPD was supported by graduate assistantships during the duration of the study. Funding sources played no role in the design, implementation, or analysis of the study, and provided no input on this manuscript. Publication costs were provided in part by the UWM Open-Access Publication Fund.

\section{Publisher's Note}

Springer Nature remains neutral with regard to jurisdictional claims in published maps and institutional affiliations.

Received: 8 April 2017 Accepted: 29 June 2017

Published online: 17 July 2017

\section{References}

Agresti A. Analysis of ordinal categorical data. 2nd ed. Hoboken: Wiley; 2010. Barnes ME, Brownell SE. Practices and perspectives of college instructors on addressing religious beliefs when teaching evolution. Cell Biol Educ. 2016;15(2):ar18. doi:10.1187/cbe.15-11-0243.

Barnes ME, Elser J, Brownell SE. Impact of a short evolution module on students' perceived conflict between religion and evolution. Am Biol Teach. 2017;79(2):104-11. doi:10.1525/abt.2017.79.2.104.

Barone LM, Petto AJ, Campbell BC. Predictors of evolution acceptance in a museum population. Evol Educ Outreach. 2014;7(1):23. doi:10.1186/ s12052-014-0023-2.

Carter BE, Wiles JR. Scientific consensus and social controversy: exploring relationships between students' conceptions of the nature of science, biological evolution, and global climate change. Evol Educ Outreach. 2014;7:6. doi:10.1186/s12052-014-0006-3.

Cavallo AM, McCall D. Seeing may not mean believing: examining students' understandings \& beliefs in evolution. Am Biol Teach. 2008;70(9):522-30 doi:10.1662/0002-7685-70.9.522.

Deniz H, Donnelly LA, Yilmaz I. Exploring the factors related to acceptance of evolutionary theory among Turkish preservice biology teachers: toward a more informative conceptual ecology for biological evolution. J Res Sci Teach. 2008:45(4):420-43. doi:10.1002/tea.20223.

Dobzhansky T. Nothing in biology makes sense except in the light of evolution. Am Biol Teach. 1973;35(3):125-9. doi:10.2307/4444260.

Gallup. Evolution, creationism, intelligent design (In depth: topics A to Z). Gallup. 2014. http://www.gallup.com/poll/21814/evolution-creationismintelligent-design.aspx. Accessed 5 Sep 2016.

Glaze AL, Goldston MJ, Dantzler J. Evolution in the southeastern USA: factors influencing acceptance and rejection in pre-service science teachers. Int J Sci Math Educ. 2015;13(6):1189-209. doi:10.1007/s10763-014-9541-1.

Graffin G. Monism, atheism, and the naturalist world-view: perspectives from evolutionary biology (Ph.D.). Ithaca: Cornell University; 2003.

Grose EC, Simpson RD. Attitudes of introductory college biology students towards evolution. J Res Sci Teach. 1982;19(1):15-24. doi:10.1002/ tea.3660190103.

Hawley PH, Short SD, McCune LA, Osman MR, Little TD. What's the Matter with Kansas?: the development and confirmation of The Evolutionary Attitudes And Literacy Survey (EALS). Evol Educ Outreach. 2011;4(1):117-32. doi:10.1007/s12052-010-0294-1.

Heddy BC, Nadelson LS. The variables related to public acceptance of evolution in the United States. Evol Educ Outreach. 2013;6(1):1-14. doi:10.1186/1936-6434-6-3.

Huitema BE. The analysis of covariance and alternatives. 2nd ed. Hoboken: Wiley; 2011

John OP, Naumann LP, Soto CJ. Paradigm shift to the integrative big-five trait taxonomy: history, measurement, and conceptual issues. In: John OP, Robins RW, Pervin LA, editors. Handbook of personality theory and research. 3rd ed. New York: Guilford Press; 2008. p. 114-58.

Johnson RL, Peeples EE. The role of scientific understanding in college: student acceptance of evolution. Am Biol Teach. 1987;49(2):93-8. doi:10.2307/4448445.
Kline RB. Beyond significance testing: reforming data analysis methods in behavioral research. Washington: Am Psychol Assoc; 2004.

Matthews M. Editorial. Sci Educ. 1997;6(4):323-9. doi:10.1023/A:1008627112693.

Mazur A. Believers and disbelievers in evolution. Polit Life Sci. 2004;23(2):55-61. doi:10.2990/1471-5457(2004)23[55:BADIE]2.0.CO;2.

Moore R, Brooks DC, Cotner S. The relation of high school biology courses \& students' religious beliefs to college students' knowledge of evolution. Am Biol Teach. 2011;73(4):222-6. doi:10.1525/abt.2011.73.4.7.

Myers JL, Well AD. Research design and statistical analysis. 2nd ed. Mahwah: Lawrence Erlbaum Associates Inc:; 2003.

Nehm RH, Schonfeld IS. Does increasing biology teacher knowledge of evolution and the nature of science lead to greater preference for the teaching of evolution in schools? J Sci Teach Educ. 2007;18(5):699-723. doi:10.1007/s10972-007-9062-7.

Pigliucci M. Denying evolution: creationism, scientism, and the nature of science. Sunderland: Sinauer Associates Inc; 2008.

Rutherford A. Introducing ANOVA and ANCOVA: a GLM approach. Thousand Oaks: SAGE Publications Inc; 2001

Rutledge ML, Mitchell MA. High school biology teachers' knowledge structure, acceptance \& teaching of evolution. Am Biol Teach. 2002;64(1):21-8. doi:10.2307/4451231.

Rutledge ML, Sadler KC. Reliability of the Measure of Acceptance of the Theory of Evolution (MATE) instrument with university students. Am Biol Teach. 2007;69(6):332-5. doi:10.2307/4452173.

Rutledge ML, Warden MA. The development and validation of the measure of acceptance of the theory of evolution instrument. School Sci Math. 1999;99(1):13-8. doi:10.1111/j.1949-8594.1999.tb17441.x.

Rutledge ML, Warden MA. Evolutionary theory, the nature of science \& high school biology teachers: critical relationships. Am Biol Teach. 2000;62(1):23-31. doi:10.2307/4450822.

Short SD, Hawley PH. Evolutionary Attitudes and Literacy Survey (EALS): development and validation of a short form. Evol Educ Outreach. 2012:5(3):419-28. doi:10.1007/s12052-012-0429-7.

Sinatra GM, Southerland SA, McConaughy F, Demastes JW. Intentions and beliefs in students' understanding and acceptance of biological evolution. J Res Sci Teach. 2003;40(5):510-28. doi:10.1002/tea.10087.

Strack F." Order effects" in survey research: activation and information functions of preceding questions. In: Schwarz N, Sudman S, editors. Context effects in social and psychological research. New York: Springer; 1992. p. 23-34.

Trani R. I won't teach evolution; it's against my religion. and now for the rest of the story. Am Biol Teach. 2004;66(6):419-27. doi:10.2307/4451708.

Wiles JR. Gifted students' perceptions of their acceptance of evolution changes in acceptance, and factors involved therein. Evol Educ Outreac. 2014:2014(7):4. doi:10.1186/s12052-014-0004-5.

Wiles JR, Alters B. Effects of an educational experience incorporating an inventory of factors potentially influencing student acceptance of biological evolution. Int J Sci Educ. 2011;33(18):2559-85. doi:10.1080/09500693.20 11.565522.

\section{Submit your manuscript to a SpringerOpen ${ }^{\circ}$ journal and benefit from:}

- Convenient online submission

- Rigorous peer review

- Open access: articles freely available online

- High visibility within the field

- Retaining the copyright to your article

Submit your next manuscript at $\boldsymbol{\nabla}$ springeropen.com 